\title{
A New Approach for Removing Anionic Organic Dyes from Wastewater Based on Electrostatically Driven Assembly
}

Sira Sansuk, Somkiat Srijaranai, and Supalax Srijaranai*

Materials Chemistry Research Center, Department of Chemistry and Center of Excellence for Innovation in Chemistry, Faculty of Science, Khon Kaen University, Khon Kaen 40002, Thailand

Summary: Number of Pages $=2$

Number of Figures $=2$

Number of Table $=0$ 


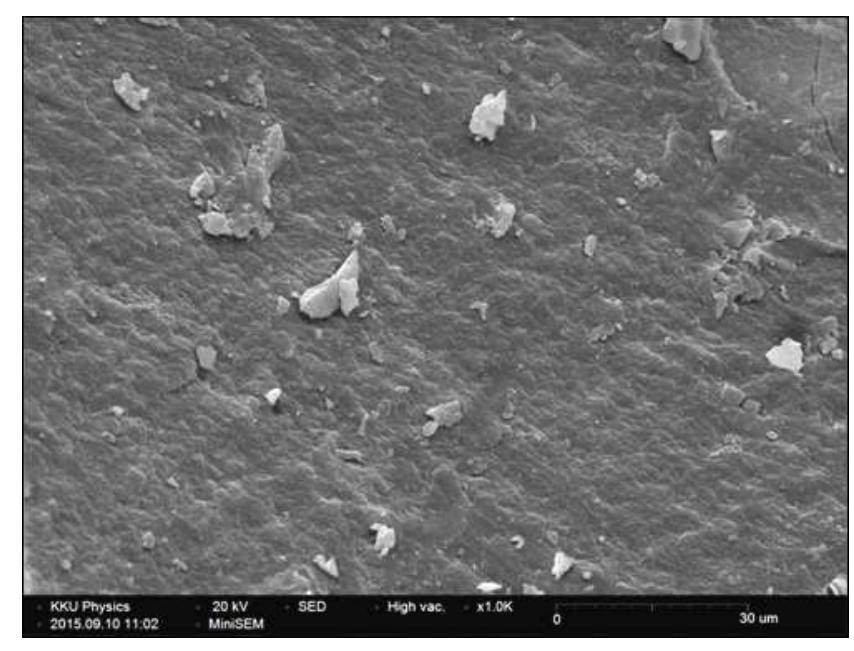

Figure S1. SEM image of $\mathrm{Cl}^{-}-\mathrm{LDH}$ precipitate.

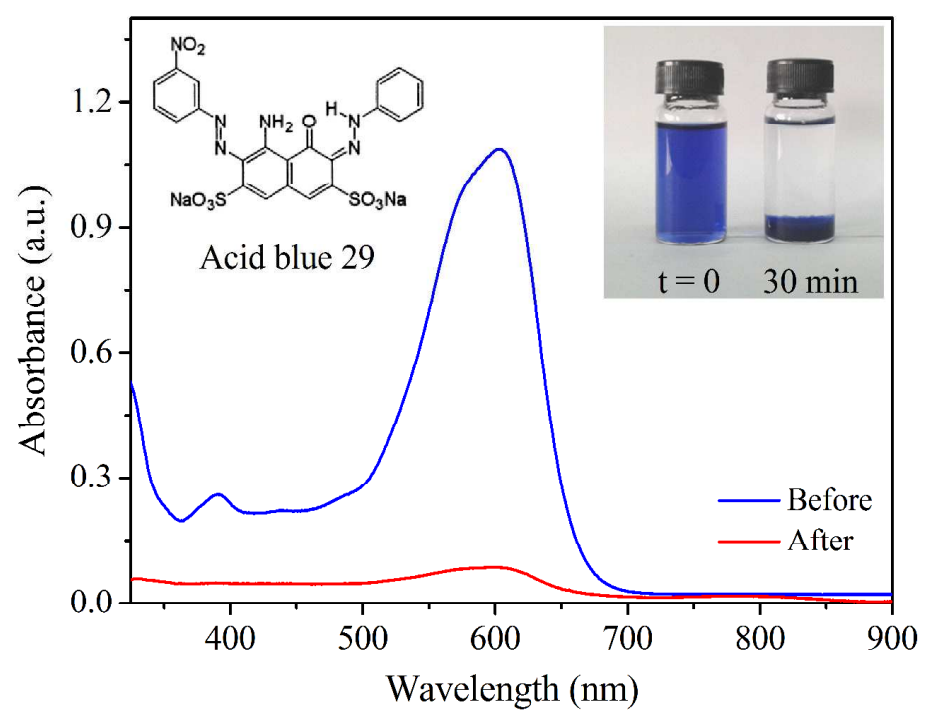

Figure S2. UV-vis spectra with corresponding photo image (Inset) of an azo dye, acid blue 29 (AB29), at an initial concentration of $100 \mathrm{mg} \mathrm{L}^{-1}$ before (blue solid line) and after $30 \mathrm{~min}$ removal time (red solid line) by using $\mathrm{NO}_{3}{ }^{-} \mathrm{LDH}$ as sorbent. 